\title{
PEDAGOGIA DA ALTERNÂNCIA E A FORMAÇÃO DO JOVEM DO CAMPO
}

\author{
Elisson Costa Alves - UEL ${ }^{1}$ \\ elissoncostaalves@gmail.com \\ Gabrieli Cristina Esteves - UEL ${ }^{2}$ \\ gabrielicesteves@gmail.com \\ Sandra Regina de Oliveira Garcia - UEL ${ }^{3}$ \\ sandragarciapr@hotmail.com
}

\section{RESUMO}

Este artigo apresenta os resultados parciais de um recorte da pesquisa que estamos realizando sobre: A prática Pedagógica como mediação entre o conhecimento científico e o conhecimento tácito, tendo a Pedagogia da Alternância desenvolvida pelas Casas Familiares Rurais - CFR do Paraná como foco do trabalho. Como parte de nossas análises buscamos compreender se esta metodologia traz alguma contribuição concreta na formação dos jovens e quais os possíveis impactos na vida dos mesmos. Nosso caminho metodológico foi primeiro o de compreender a Educação do Campo e seus grandes desafios no Brasil e a Pedagogia da Alternância que se coloca como uma alternativa para os jovens do campo nele permanecerem a partir outras condições, tendo uma relação indissociável do conhecimento científico e tácito na condução do processo formativo, o que levaria estes jovens a autonomia intelectual e consequentemente a sua emancipação. Num segundo momento ouviremos as famílias e os jovens no sentindo de compreendermos se a proposta da Pedagogia da Alternância tem um campo fértil para sua materialização. Os resultados parciais apontam que a Educação do Campo no Brasil ainda não se constituiu como política de acesso a todos e que as CFRs no Paraná tem se aproximado das expectativas das famílias e dos jovens do campo.

Palavras Chave: Pedagogia da alternância, educação do campo, emancipação.

\section{INTRODUÇÃO}

Este estudo faz parte da pesquisa: A Prática Pedagógica como mediação entre o Conhecimento Científico e o Conhecimento Tácito: metodologias para a Pedagogia do Trabalho, que tem como objetivo analisar se a relação presente na proposta dessa metodologia, onde o conhecimento tácito e o conhecimento científico se imbricam possibilita uma formação emancipadora. Busca compreender, portanto, os possíveis

\footnotetext{
${ }^{1}$ Graduando em Pedagogia pela Universidade Estadual de Londrina, membro do Grupo de Pesquisa de Trabalho e Educação - GPETE e colaborador na pesquisa: A Prática Pedagógica como mediação entre o Conhecimento Científico e o Conhecimento Tácito: metodologias para a Pedagogia do Trabalho,

${ }^{2}$ Graduanda em Pedagogia pela Universidade Estadual de Londrina, membro do Grupo de Pesquisa de Trabalho e Educação - GPETE e colaboradora na pesquisa: A Prática Pedagógica como mediação entre o Conhecimento Científico e o Conhecimento Tácito: metodologias para a Pedagogia do Trabalho.

${ }^{3}$ Docente do Departamento de Educação da Universidade Estadual de Londrina - UEL, Doutora em Educação pela Universidade Federal do Paraná, Coordenadora do Grupo de Pesquisa de Trabalho e Educação - GPETE e Coordenadora da pesquisa: A Prática Pedagógica como mediação entre o Conhecimento Científico e o Conhecimento Tácito: metodologias para a Pedagogia do Trabalho.
} 


\section{SEMINÁRIO DE PESQUISA EM CIÊNCIAS HUMANAS - SEPECH \\ Humanidades, Estado e desafios didático-científicos \\ Londrina, 27 a 29 de julho de 2016}

impactos que essa modalidade metodológica pode ter na formação dos filhos dos pequenos agricultores, ou seja, a maneira que essa metodologia afeta a formação dos jovens do campo.

O nosso recorte tem como objetivo entender se esta metodologia contribui de forma concreta na formação dos jovens filhos de agricultores familiares, considerando a relação e a articulação indissociável entre trabalho e educação.

Essa constante articulação entre trabalho e educação, é uma das propostas da Pedagogia da Alternância em seu conceito de formação teórico-prático, na perspectiva da práxis, onde aborda a teoria e a prática numa mesma dimensão, integrando a teoria com a realidade local, ou seja, todo trabalho realizado dentro das CFRs é em constante diálogo com a realidade da comunidade e da família dos alunos, que a partir desta relação, ao mesmo tempo em que se apropriam do conhecimento científico, resignificam e transformam a prática do trabalho.

No Paraná as Casas Familiares Rurais iniciam a partir de 2006 a integração do Ensino Médio à Educação Profissional ofertando cursos técnicos nas áreas de Agropecuária, Gestão Ambiental e Agroindústria.

A intenção foi de possibilitar ao jovem do campo o acesso à formação técnica ao mesmo tempo do processo de escolarização no ensino médio. A integração curricular propõe que no mesmo currículo os conhecimentos básicos e técnicos componham a totalidade formativa superando a fragmentação do conhecimento e compreendendo que a profissionalização não pode ser restrita ao mercado de trabalho. É a perspectiva de uma formação integrada, enquanto currículo e integral enquanto concepção de formação omnilateral, ou seja, na sua totalidade.

Inicialmente enfocaremos a Educação do Campo como uma demanda dessa população, em que o Ensino Médio ainda não é uma realidade concreta, por isso, ainda há uma forte presença dos movimentos sociais como além de demandantes desta oferta, os principais ofertantes, tendo o poder público como um parceiro neste processo.

De acordo com a Secretaria de Estado da Educação do Paraná (2006) o propósito de aprimorar o convênio com a ARCAFAR/Sul de implantação dos cursos técnicos integrados a Educação Profissional, assim como, o da ampliação do número de CFRs foi primeiro atender a população do campo na etapa conclusiva da Educação Básica, o Ensino Médio e de se apropriar da metodologia para que a rede pública fosse gradativamente incorporando-a para que a mesma assumisse o seu papel de atendimento a esta modalidade, a Educação do Campo.

\section{A EDUCAÇÃO DO CAMPO NO BRASIL: CAMINHOS PERCORRIDOS}

De acordo com MUNARIM (2006, p. 20), é preciso superar a visão da cidade como local de desenvolvimento e o rural espaço do atraso. Também afirma que as políticas voltadas para o meio rural tem sempre o objetivo de extrair do campo o maior benefício para a vida na cidade, ou da busca de urbanizar o espaço rural. Superar a visão de que o campo é lugar do atraso ou de que é suficiente política de transporte escolar para atender a população do campo, ainda é um grande desafio, apesar dos avanços que ocorreram principalmente na legislação brasileira.

Após um longo tempo de luta e de reivindicações, por meio dos movimentos sociais do campo, a educação começa a entrar na agenda de discussões para a elaboração de politicas educacionais. 


\title{
XI SEMINÁRIO DE PESQUISA EM CIÊNCIAS HUMANAS - SEPECH \\ Humanidades, Estado e desafios didático-científicos \\ Londrina, 27 a 29 de julho de 2016
}

De acordo com KOLLING; NERY; MOLINA (1999) o movimento buscou uma educação que fosse voltada para os interesses do campo.

\begin{abstract}
A luta desse movimento busca conceber a educação básica do campo, voltada ao interesse do campo, voltada ao interesse e ao desenvolvimento sociocultural e econômico dos povos que habitam e trabalham no campo, atendendo às suas diferenças históricas e culturais para que vivam com dignidade e para que, organizados, resistam contra a exploração e a expropriação, ou seja, este do campo tem o sentido do pluralismo das ideias e das concepções pedagógicas: diz respeito à identidade dos grupos formadores da sociedade brasileira. (KOLLING; NERY; MOLINA 1999, p. 28-29).
\end{abstract}

A Constituição de 1988 foi um marco das conquistas quando define a garantia da educação como direito de todos. A partir da compreensão constitucional da educação como direito de todos os brasileiros, inicia-se o reconhecimento da educação do/no campo respeitando os saberes, a cultura as especificidades do local onde vivem.

Caldart (2002) compreende que para os povos do campo devem ter políticas no e do campo, segundo a autora no campo, porque a população que lá vive tem o direito a ter educação onde vive e do campo, porque é preciso que seja pensada desde o seu lugar e com a participação vinculada a sua cultura e as suas necessidades humanas e sociais.

\section{A EDUCAÇÃO DO CAMPO NAS DIRETRIZES OPERACIONAIS}

A educação do campo, tratada como educação rural na legislação brasileira, tem um significado que incorpora os espaços da floresta, da pecuária, das minas e da agricultura, mas os ultrapassa ao acolher em si os espaços pesqueiros, caiçaras, ribeirinhos e extrativistas. O campo, nesse sentido, mais do que um perímetro não urbano, é um campo de possibilidades que dinamizam a ligação dos seres humanos com a própria produção das condições da existência social e com as realizações de sociedade humana. (Brasil, 2002, p. 1)

O parecer 36/2001 das Diretrizes Curriculares Nacionais da Educação Básica foi elaborado para dar concretude ao art. 28 da LDB, 9394/96 que propôs medidas de adequação da escola à vida do campo, pois no Brasil historicamente a educação do campo foi ignorada.

O avanço conquistado na LDB e nas demais legislações posteriores, foi resultado da luta dos Movimentos Sociais e das experiências que os mesmos vinham realizando, conseguiram que a legislação incorporasse o conceito de que a discussão do campo não se refere apenas à questão do perímetro não urbano, mas sim um campo de possibilidades que faz ligação com dos sujeitos, a própria produção das condições da existência social e com as realizações da sociedade.

Um resultado importante deste movimento foi à elaboração do Parecer n.36/2001 e da Resolução n.1/2002 do Conselho Nacional de Educação - CNE que definiu as Diretrizes Operacionais para a Educação Básica nas Escolas do Campo. As 


\section{SEMINÁRIO DE PESQUISA EM CIÊNCIAS HUMANAS - SEPECH \\ Humanidades, Estado e desafios didático-científicos \\ Londrina, 27 a 29 de julho de 2016}

Diretrizes trouxeram identidade para a Escola do Campo, pois vincularam as questões da sua realidade ancoradas na temporalidade e saberes próprias dos estudantes.

A identidade da escola do campo é definida pela sua vinculação às questões inerentes a sua realidade, ancorando-se temporalidade e saberes próprios dos estudantes, na memória coletiva que sinaliza futuros, na rede de ciência e tecnologia disponível na sociedade e nos movimentos sociais em defesa de projetos que associem as soluções exigidas por essas questões à qualidade social da vida coletiva no país. (Brasil, p.42, 2002)

\section{O movimento por uma Educação do Campo de acordo com Caldart}

...nasceu tomando/precisando tomar posição no confronto de projetos de campo: contra a lógica do campo como lugar de negócio, que expulsa as famílias, que não precisa de educação nem de escolas porque precisa cada vez menos de gente, a afirmação da lógica da produção para a sustentação da vida nas suas diferentes dimensões, necessidades, formas. (CALDART, 2002,p.16)

As conquistas em relação à educação do campo visa diminuir o abismo do nível de escolaridade entre o campo e a cidade, e que mesmo tardia, traz ao segmento da agricultura familiar, que tanto sofreu com a falta de politicas públicas, um alento quanto à possibilidade de seus filhos acessarem uma educação que dialogue com a sua realidade.

A possibilidade dos jovens do campo, terem acesso ao seu processo de escolarização no próprio campo, além de suprir a deficiência da escolaridade dos que vivem no campo, visa à melhoria das condições de vida, relacionando aquilo que se aprende na escola, o conhecimento científico com o conhecimento tácito, a realidade do trabalho da família na propriedade, elevando o desenvolvimento rural e possibilitando a permanência dos jovens no campo e, é nesse contexto que a Pedagogia da Alternância se faz presente.

Considerando a especificidade da Educação do Campo, é necessário que o currículo seja pensado a partir da sua realidade, assim como, os próprios profissionais da educação que nela atuam também precisam ter uma formação que possibilite a compreensão da realidade. Quanto a isto Ribeiro (2010) chama a atenção de como a Pedagogia da Alternância valoriza a formação dos educadores. Outros movimentos sociais também optam pela formação dos seus educadores, por entenderem que as Universidades formam os professores que não conhecem e não dialoga com as especificidades da educação do campo, outro exemplo vem do Movimento Sem Terra MST.

Portanto, a Pedagogia da Alternância, em tese, articula prática e teórica em uma práxis. Esse método, em que se alternam situações de aprendizagem escolar com situações de trabalho produtivo, exige uma formação específica para os professores, que as licenciaturas, de modo geral, não oferecem sindicatos, associações, organizações sociais que adotam a Pedagogia da Alternância optam pela contratação de monitores, que, de modo geral, são agrônomos ou técnicos agrícolas. Os licenciados que escolhem trabalhar com a Pedagogia da Alternância 


\section{SEMINÁRIO DE PESQUISA EM CIÊNCIAS HUMANAS - SEPECH \\ Humanidades, Estado e desafios didático-científicos \\ Londrina, 27 a 29 de julho de 2016}

fazem cursos oferecidos por aquelas entidades e/ou organizações. (RIBEIRO, 2010, p.76).

A formação do profissional que atua na Casa Familiar Rural - CFR é ministrada pela coordenação pedagógica da ARCAFAR/Sul. Essa formação é baseada no diálogo entre professores (da rede publica cedidos para a CFR) e monitores (contratados pela ARCAFAR/Sul), a fim de que não cause a fragmentação do conhecimento.

De acordo com Nosella (2007, p. 08):

O monitor das CFR's tem como primeira característica o compromisso político e técnico com o movimento, com a população do campo. Ele tem que conhecer bem, ter familiaridade com os princípios filosóficos e metodológicos e com os instrumentos pedagógicos da alternância.

Os princípios filosóficos impõem aos monitores das CFRs, certo caráter reflexivo de militância, ou seja, um olhar mais atento e crítico sobre os reais fatores que desencadearam o surgimento da Educação do Campo.

O conceito de educação do campo vem sendo construído nos movimentos sociais organizados na Via Campesina - Brasil. Campo, para esses movimentos, tem uma conotação política de continuidade e identidade com a história das lutas camponesas internacionais e está explicitado nas Diretrizes Operacionais para a Educação Básica nas Escolas do Campo. (RIBEIRO, 2010,p.34).

Apesar dos avanços na legislação ainda há um parcial "esquecimento" da Educação do Campo/rural, pelas instâncias educacionais públicas municipais e estaduais responsáveis pela Educação Básica. As principais experiências de educação rural/do campo, foram promovidas por sujeitos políticos coletivos, ou seja, pelos movimentos sociais populares, dentre tantos movimentos sociais que lutam por uma Educação do Campo a influência do Movimento dos Trabalhadores Rurais Sem Terra - MST são inquestionáveis.

De acordo com Souza (2008):

Os movimentos sociais, expressivamente o Movimento dos Trabalhadores.

Rurais Sem-Terra (MST) demandam do Estado iniciativas no âmbito da oferta de educação pública e da formação de profissionais para trabalhar nas escolas localizadas no campo. Nos dias atuais, Secretarias Municipais e Estaduais de Educação têm organizado eventos de formação continuada de professores e seminários objetivando a discussão/ construção de políticas públicas da educação do campo.

A princípio tais movimentos sociais lutavam pelo direito á terra, posteriormente, colocaram também como pauta de luta, o direito á uma educação digna e adequada para a realidade campesina desses sujeitos políticos.

A criação das Casas Familiares Rurais - CFRs vem no bojo de experiências metodológicas que vão sendo viabilizadas pelos movimentos sociais para atender a população do campo na perspectiva de uma educação emancipadora, possibilitando a o acesso ao processo educativo no e do campo. 


\section{SEMINÁRIO DE PESQUISA EM CIÊNCIAS HUMANAS - SEPECH \\ Humanidades, Estado e desafios didático-científicos \\ Londrina, 27 a 29 de julho de 2016}

\section{AS CASAS FAMILIARES RURAIS E A PEDAGOGIA DA ALTERNÂNCIA}

No Brasil, a Pedagogia da Alternância ainda é recente e pouco conhecida pelas pessoas, inclusive os professores e acaba se tornando restrita aos sujeitos nela envolvidos.

Em 1935 inicia na França a discussão da Pedagogia da Alternância como resultado da insatisfação dos filhos de agricultores com o modelo educacional francês que pouco considerava o meio rural, onde os jovens não se sentiam motivados para frequentar uma escola em que os conteúdos não tinham significado para a sua vida tanto pessoal como profissional.

Sendo assim, surge a Pedagogia da Alternância como uma forma de educação escolar capaz de atender às especificidades educacionais para jovens agricultores, integrando o conhecimento tácito ao conhecimento científico, possibilitando de acordo com a proposta elaborada uma formação teórico-prática, capaz de dar significado à vida desse jovem e ajudá-lo na sua vida profissional.

Em 1969, depois de decorrido longos anos em que a Pedagogia da Alternância começou a tomar forma, ela surge no Brasil, no estado do Espírito Santo, onde foram estruturadas as três primeiras Escolas Famílias Agrícolas.

Somente em 1987 é que a Pedagogia da Alternância teve início no Paraná no município de Barracão na região sudoeste do estado, e que mesmo decorridos longos anos, ainda é uma proposta pedagógica pouco conhecida no meio acadêmico.

A alternância não acontece apenas nas CFR's, pois outras instituições a utilizam, porém a Pedagogia da Alternância é exclusiva das CFR's com seus métodos e instrumentos, onde se pratica a Alternância Integrativa, também chamada de Alternância Real, que visa integrar o trabalho e o estudo, pois ambos devem se integram de forma orgânica.

\section{A FORMAÇÃO DOS FILHOS DOS PEQUENOS AGRICULTORES PELA PEDAGOGIA DA ALTERNÂNCIA}

A educação do campo que se desenvolve através da Pedagogia da Alternância, busca a formação do jovem (filhos dos pequenos agricultores), através do seu meio familiar, sem desvincular o mesmo do campo, espaço onde vive, buscando através do confronto entre os saberes científicos com os saberes tácitos uma formação sólida, formando sujeitos autônomos e consequentemente emancipados, tendo, portanto instrumentos que possibilite a transformação do meio em que vivem.

O período alternado entre a vivência e estudo na escola, família e comunidade é chamado de alternância, que tem por objetivo envolver as famílias na educação dos filhos, fortalecendo a prática do diálogo entre as diferentes pessoas que participam dos processos de formação dos jovens, proporcionando a escolarização integrada a formação técnica para os, filhos dos pequenos agricultores.

O objetivo é possibilitar a agricultura familiar o acesso aos conhecimentos científicos e tecnológicos, mas também de que o jovem tenha a possibilidade, se assim for desejada, de permanecerem no campo, contribuindo com o trabalho na propriedade, ajudando na subsistência e renda familiar. Uma formação que possibilita que o jovem valorize o seu modo de vida e consiga ver o significado entre aquilo que aprende, 


\section{SEMINÁRIO DE PESQUISA EM CIÊNCIAS HUMANAS - SEPECH \\ Humanidades, Estado e desafios didático-científicos \\ Londrina, 27 a 29 de julho de 2016}

fazendo ligação entre os conhecimentos do trabalho da família e da comunidade com os conhecimentos sistematizados e assim, despertando a consciência crítica.

De acordo com a ARCAFAR/Sul, a Pedagogia baseada na alternância pode se constituir como uma metodologia mais adequada para atingir a consciência crítica, e materializar a concepção de educação do campo no campo. Isso porque a alternância é de tempo, de local e de formação, com momentos de aprendizagem nas CFR's, na comunidade e na propriedade familiar.

Por fim, a Pedagogia da Alternância também articula prática e teoria numa práxis e realiza-se em tempos e espaços que se alternam entre escola e propriedade, comunidade, assentamento, acampamento ou movimento social ao qual o educando está vinculado. (RIBEIRO, 2010,p. 84).

Sendo assim, a formação por alternância deve ser contínua, onde o jovem utiliza o espaço escolar para o momento de reflexão teórica e de aprofundamento das questões relevantes de interesses deles e das famílias, utilizando o espaço familiar para o momento de confronto da teoria com a prática.

Essa alternância possibilita ao jovem do campo um processo de emancipação e autonomia, no sentido grego da palavra autos (por si mesmo) e nómos (regulamento, norma, lei), é o que define Liberdade como possibilidade de independência, ou seja, ele próprio começa a ser autor de sua independência em relação ao seu trabalho sobre a propriedade de sua família, nota-se então, a constante relação entre trabalho-educação, relação esta que deve ser pensada e praticada com base na realidade da comunidade.

Do mesmo modo que a educação rural/do campo, a pedagogia da alternância é uma expressão polissêmica. Apresenta elementos comuns, como a articulação entre o tempo destinado ás atividades escolares e o tempo destinado ás atividade de trabalho. Mas essas atividades se realizam de maneiras diversas, de acordo com os sujeitos que as assumem, as regiões onde ocorrem experiências, as condições que possibilitam ou restringem e até impedem a sua realização, e as concepções teóricas que fundamentam suas práticas. (RIBEIRO, 2010, p.92).

Na Lei de Diretrizes e Bases para a Educação Nacional - LDB nº 9.394/96, em seu Capítulo II Da Educação Básica, Seção I, propõe:

Art. 28. Na oferta de educação básica para a população rural, os sistemas de ensino promoverão as adaptações necessárias á sua adequação ás peculiaridade da vida rural e de cada região, especialmente:

I - conteúdos curriculares e metodologias apropriadas ás reais necessidades e interesses dos alunos da zona rural;

II - organização escolar própria, incluindo adequação do calendário escolar ás fases do ciclo agrícola e as condições climáticas;

III - adequação á natureza do trabalho na zona rural;

Ainda referente à seção da Educação Básica consta na LDB: 


\section{SEMINÁRIO DE PESQUISA EM CIÊNCIAS HUMANAS - SEPECH \\ Humanidades, Estado e desafios didático-científicos \\ Londrina, 27 a 29 de julho de 2016}

Art. 23. $\S 2^{\circ} \mathrm{O}$ calendário escolar deverá adequar-se ás peculiaridades locais, inclusive climáticas e econômicas, a critério do respectivo sistema de ensino, sem com isso reduzir o número de horas letivas previsto nesta Lei.

Quanto a isso o CNE aprovou em 2006 o parecer 1/2006 referente ao reconhecimento da Pedagogia da Alternância, reconhecendo que o tempo da alternância se constitui como dias letivos. Isto se constituiu em importante conquista para a Pedagogia da Alternância respaldada no art.28 da LBB citado acima. Isto foi possível porque a carga horária é bem diferente do ensino regular, ela ultrapassa os duzentos dias letivos e às oitocentas horas exigidas pela $\mathrm{LDB}$, onde os períodos vivenciados na escola e na família/comunidade são contabilizados como dias letivos e horas, considerando tudo que é realizado fora da sala de aula.

Todas as atividades realizadas fora da sala de aula são executadas mediante trabalhos práticos e pesquisas, com auxilio de roteiros que compõem um Plano de Estudo.

Já o Plano Curricular ou Plano de Formação, possui as matérias básicas e da formação técnica, de acordo com as características de cada instituição que é formulado com base nos conteúdos definidos em nível nacional para o Ensino Médio.

O Plano de Estudo, executado pelo jovem, há o período das semanas na propriedade que oportuniza os jovens discutirem sua realidade junto com a família, levando a reflexões, planejando soluções e realizando experiências dentro de seu contexto, já o período em que o jovem permanece em regime de internato ou semiinternato, no centro de formação, ou seja, na escola, é onde tem a oportunidade de socializar a sua realidade baseada em pesquisas e trabalhos realizados durante a permanência no meio familiar.

O auxílio de monitores/formadores nesse processo é de extrema importância, pois o aluno levanta as situações vivenciadas na realidade familiar, partindo de senso comum para compreender o conhecimento científico.

Portanto, o parecer 1/2006 deixa claro que os CEFFAs têm por objetivo desenvolver a relação entre a teoria e a prática, no qual jovem também é orientado na elaboração do seu projeto profissional de vida, especialmente por meio de visitas às famílias durante os períodos de alternância.

Sendo assim, são utilizados alguns instrumentos pedagógicos para que seja alcançado o conhecimento científico, partindo do senso comum e desenvolvendo uma consciência crítica/ emancipação como: Plano de Formação, Plano de estudo, Colocação em comum (socialização e organização dos conhecimentos da realidade do aluno e do seu meio, que servem de base para o aprofundamento articulado nas várias áreas do saber; interdisciplinaridade), Caderno de síntese da realidade do aluno, Fichas didáticas, Visitas de estudo, Intervenções externas (palestras, seminários, debates), Experiências (Projeto Profissional do Aluno), Visitas à família do aluno, Caderno de acompanhamento da alternância e a avaliação que deve ser contínua e permanente.

É notável que, embora seja uma modalidade da educação escolar básica, a educação do campo, deve ser pensada e planejada para que seja aplicada no campo, levando em consideração a realidade vigente, que faz com que seja necessário uma (re) organização e (re) adequação que parte dos conceitos teóricos, sendo o Plano de 


\section{SEMINÁRIO DE PESQUISA EM CIÊNCIAS HUMANAS - SEPECH \\ Humanidades, Estado e desafios didático-científicos \\ Londrina, 27 a 29 de julho de 2016}

formação (currículo), e se estende a prática, voltando-se para as metodologias, uma delas, a Pedagogia por Alternância.

São vários fatores que fazem os jovens optarem pelas CFR's, por ser algo que mais se aproxima de sua realidade, os jovens são os sujeitos sociais que buscam essa formação por alternância, por razões sociais de militância em relação á realidade/ história campesina.

Os sujeitos da Educação do campo são aquelas que sentem na própria pele os efeitos dessa realidade perversa, mas que não se conformam com ela. São os sujeitos da resistência no e do campo: sujeitos que lutam para continuar sendo agricultores apesar de um modelo de agricultura cada vez mais excludente; sujeitos da luta pela Terra e da Reforma Agrária; sujeitos da luta por melhores condições de trabalho no campo; sujeitos da resistência na terra dos quilombos e pela identidade própria desta herança; sujeitos da luta pelo direito de continuar a ser indígena e brasileiro, em terras demarcadas e em identidades e direitos sociais respeitados, e sujeitos de tantas outras resistências, culturais, políticas e pedagógicas. (KOLLING; CERIOLI; CALDART, p. 45,2002)

A formação por alternância, não é apenas a permanência no campo, mas a luta por uma democracia que alcance a todos os cidadãos, em todos os sentidos, indiferente á quais classes sociais estes pertencem, a militância por uma educação do campo, é uma mensagem que claramente diz.

Somos camponeses, agricultores, cidadãos e brasileiros, portadores de direitos, deveres e necessidades, como qualquer outro ser humano. Nossas mãos estão sujas de terra, e é por essa terra que lutamos, por essa autonomia e liberdade sobre nosso próprio trabalho, lutamos por igualdade: igualdade no mercado de trabalho, no reconhecimento histórico, na educação, queremos e lutaremos por uma igualdade social, também somos parte do povo brasileiro.

\section{ALGUMAS CONSIDERAÇÕES}

A Educação no Brasil, ainda é um grande desafio e, no campo este desafio se apresenta ainda maior. No entanto, dados do censo INEP (2012) demonstram que apesar de $96,2 \%$ dos jovens que matriculados no ensino médio serem na zona urbana, 3,8\% são jovens do campo, mesmo assim, se constata nesta década um movimento de crescimento de matrículas de jovens do campo no Ensino Médio.

A concentração de matrículas na zona urbana é coerente com a distribuição mais geral da população, cuja maioria encontra-se nas cidades, como revela o Censo IBGE 2010. Ao mesmo tempo, há um contingente de alunos que se desloca da zona rural para estudar em escolas da zona urbana e este deve ser um fator a considerar nesta distribuição. Por outro lado, vale registrar que parece estar em andamento uma expansão do ensino médio na zona rural, pois houve 


\section{SEMINÁRIO DE PESQUISA EM CIÊNCIAS HUMANAS - SEPECH \\ Humanidades, Estado e desafios didático-científicos \\ Londrina, 27 a 29 de julho de 2016}

crescimento em termos absolutos (de 99.775 para 322.479 matrículas) e relativos (de 1,2\% para 3,8\%) entre 2000 e 2012. Na zona urbana, por sua vez, registra-se redução em termos absolutos (de 8.093.173 para 8.054.373 matrículas) e relativos (de $98,8 \%$ para $96,2 \%$ ) no mesmo período. (CENSO/INEP, 2012)

As CFRs, assim como outras Instituições dos movimentos sociais, vêm desenvolvendo metodologias específicas para o atendimento do processo de escolarização da população do campo, assumindo muitas vezes o papel do Estado na oferta principalmente desta etapa da Educação Básica.

A Pedagogia da Alternância se coloca como uma alternativa para os jovens filhos de pequenos agricultores com uma proposta metodológica que leva em conta principalmente a relação entre o conhecimento tácito que o jovem trás da família e da comunidade, e o conhecimento científico construído nas CFRs.

Outro desafio da proposta da Pedagogia da Alternância é de uma formação que possibilite também a profissionalização do jovem do campo. $O$ que vem sendo desenvolvido nas CFRs do Paraná é a integração curricular do ensino médio à educação profissional, o que nos parece ser condizente com a metodologia da alternância, pois a relação entre o conhecimento tácito e o conhecimento cientifico, na perspectiva da práxis, tem os mesmos princípios da formação integral dos sujeitos num currículo integrado, superando a fragmentação dos conhecimentos.

Compreender como isto vem ocorrendo, através das vozes dos próprios jovens, é a etapa que ainda realizaremos.

\section{REFERÊNCIAS}

BRASIL. Lei de Diretrizes e Bases da Educação Nacional, nº 9.394, de 20 de dezembro de 1996.

Diretrizes Operacionais para a Educação Básica nas Escolas do Campo. Resolução CNE/CEB No 1, de 3 de Abril de 2002.

CALDART, Roseli Salete. Por uma Educação do Campo: traços de uma identidade em construção. In: KOLLING, Jorge Edgar; CERIOLI, Paulo Ricardo; CALDART, Roseli Salete. Educação do Campo: identidade e políticas públicas. Brasília: DF, 2002.

KOLLING, Edgar Jorge; CERIOLI, Paulo Ricardo; CALDART, Roseli Salete (Orgs.). Educação do Campo: identidade e políticas públicas. Por uma Educação do Campo. Col. Por uma Educação do Campo vol. 04. Brasília, 2002.

(KOLlinG; NERY; MOLINA (1999) Orgs.). A Educação Básica e o Movimento Social do Campo. Coleção Por Uma Educação Básica do Campo, $n^{0} 1$. Brasília: UnB, 1999. 


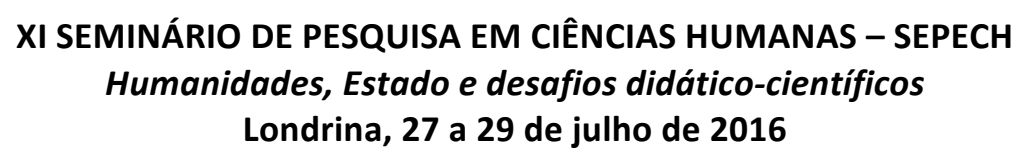

LIMA, Humberto Rodrigues. A pedagogia da alternância nas casas familiares rurais do Paraná: uma possibilidade de integração entre ensino médio e educação profissional. Dissertação de Mestrado em Educação. UFPR. Curitiba, 2013.

LIMA, Humberto Rodrigues. KUENZER, Acacia Zeneida. As relações entre o mundo do trabalho e a escola: a alternância como possibilidade de integração. Revista Educação do Centro de Educação. Vol. 38, num. 3. p. 523-535. Universidade Federal de Santa Maria, RS. Brasil, 2013.

MUNARIM, Antonio. Os campos da pesquisa em Educação do Campo: espaço e território como categorias essenciais. In: MOLINA, Mônica Castagna. Educação do Campo e pesquisa: questões para reflexão. Brasília/MDA, 2006.

NOSELLA, P. Militância e profissionalismo na educação do homem do campo. Revista da Formação por Alternância. Brasília: CEFFAs Centro Familiares de Formação por Alternância. União Nacional das Escolas Agrícolas do Brasil, ano $2-\mathrm{n}^{\circ}$ 4 , julho 2007.

RIBEIRO, Marlene. Movimento Camponês, Trabalho e Educação: liberdade, autonomia, emancipação: princípios/ fins da formação humana. $1^{\circ}$ ed. São Paulo: Expressão Popular, 2010.

RIBEIRO, Marlene. Pedagogia da alternância na educação rural/do campo: projetos em disputa. Rio Grande do Sul. Disponível em: http://www.scielo.br/pdf/ep/v34n1/a03v34n1. Acesso em: 16/04/2016.

SOUZA. M. A. Educação do Campo: políticas, práticas pedagógicas e produção científica. Disponível em: http://www.scielo.br/pdf/es/v29n105/v29n105a08.pdf . Acesso em 16/04/16. 